\title{
A pretexto de Homero
}

\author{
Under the pretext of Homer
}

\section{Tereza de Jesus Carrera Jardini}

Doutora em Literatura Portuguesa - USP; Docente nos Cursos de Letras e Tradutor/Intérprete - UNINOVE. terezajardini@uninove.br

\section{Resumo}

Este artigo aborda brevemente os conceitos de "verdade", "mentira", "ficção" e "realidade", temas recorrentes nos campos da história e da literatura, tomando como base a leitura de Homero. O objetivo do texto é salientar a relevância da literariedade sobre o biografismo, direcionando o olhar do aluno para os conteúdos que ele traz e que conseguem agradar a todos através dos tempos.

Palavras-chave: Aprendizagem. Ensino. Ficção. História. Literatura.

\section{Abstract}

This paper brings a brief study on the concepts of "truth", "lie", "fiction" and "reality", recurring issues among the fields of History and Literature, based on Homero's classical works. The aim of this study is, therefore, points the importance of literarity over biografism, turning the student's attention to the contents he/she conveys and which please many people through time.

Key words: Fiction. History. Learning. Literature. Teaching. 


\section{Introdução}

Em 1933, Marie Bonaparte (In Heidbreder, 1981, p.327) escreveu em Paris o livro Edgar Poe, sobre o escritor inglês do mesmo nome, nascido em Boston, em 1809. Trata-se de um trabalho de análise literária que segue uma trilha psicanalítica de abordagem em que, traçando um paralelo entre o homem e a obra, a autora busca, por meio do conteúdo manifesto, o conteúdo latente (inconsciente) dos textos escolhidos. Uma das análises realizadas no livro citado é sobre "O gato preto", enigmático conto de Poe escrito entre 1842 e 1843.

No trabalho diário com o ensino de literatura, é sempre esperado que os professores comentem com seus alunos que qualquer leitor aficionado à escrita de um autor não deve preocupar-se com conteúdos que podem relacionar-se à sua vida - no caso de Poe, seus dramas caseiros ou seu problema com a bebida -, quando o impacto dos contos, especialmente o citado, é o que mais impressiona. Um texto tão interessante faz sedimentar a ideia, adotada por grande parte dos estudiosos modernos de Literatura, de que o que importa é a obra.

Essa é uma questão que sempre origina polêmica nos meios acadêmicoliterários, havendo alguns críticos partidários do chamado 'biografismo' e, outros tantos, que defendem a análise da obra desligada do seu autor, no sentido de considerar que as suas características psicológicas e pessoais não têm caráter decisivo sobre seu talento para criar ficção literária.

Tentando tornar mais abrangente o exemplo, pode-se recorrer também ao que ocorre com relação às controvérsias que cercam Homero e sua obra, assunto sobre o qual nos deteremos mais longamente neste artigo. É claro que não são casos idênticos. O que se discute não são as características pessoais de Homero, de cuja biografia ou origem nada se sabe de concreto, havendo até a possibilidade de tratar-se de dois "Homeros", um para a Ilíada e outro para a Odisseia, sendo que alguns autores chegam a negar-lhe a existência. O que aproxima os dois exemplos é essa abordagem ou esse vínculo de aparência tão resistente que liga, automaticamente, vida do autor \& obra.

Quando lemos os poemas homéricos num curso de literatura é inevitável ouvir dos alunos questionamentos sobre seu autor, na tentativa de compreender o homem, o gênio reunindo elementos que a memória de um povo guardou. Cabe ao professor orientar o foco do interesse, levando os leitores a percebêlo não "condicionado" sob o texto, como Marie Bonaparte faz com Poe, mas 
polvilhado por toda a sua extensão, presente em cada frase ou parágrafo, voz que ecoa pelos versos, como naquele marcante poema do poeta parnasiano brasileiro Alberto de Oliveira que consta em qualquer antologia: "[. . . ignota voz, qual se da antiga lira / fosse a encantada música das cordas,/ qual se essa a voz de Anacreonte fosse".

No autor grego, o fundamental é fazer a leitura da "composição", que é de tal forma definitiva que fica no ar a impressão da fugacidade das questões que cercam um texto que perdura através dos tempos e perdurará. A razão dessa persistência está, sem dúvida, acima da falta de caracterização pessoal de seu autor. Está, sobretudo, no universo imaginário trabalhado por ele e na evocação de um passado de glória que o homem precisa preservar, para sentir a força de suas raízes humanas.

\section{Considerando a obra de arte em si}

Num curso de estudos literários, o professor deve sempre se preocupar em direcionar a questão para o esclarecimento de que todas as epopeias, de certa forma, tocam nesses pontos vulneráveis do homem que são a incógnita sobre sua origem e o temor de esquecer-se de seu passado. Diz Flávio Kothe (1987, p.15): "O herói épico é o sonho de o homem fazer a sua própria história [. . .]", frase que completa o que foi anteriormente colocado sobre o dilema de preencher as lacunas das perguntas sem respostas. Assim, a maior importância dos aedos primitivos e dos autores épicos que depois os seguiram na história, pode ser "[. . . ] por um lado procurar reter uma imagem de um passado morto e, por outro, desejarem ser compreendidos e acreditados [...]" (Finley, 1984, p. 19), como porta-vozes desse mesmo passado de glória, do qual os homens creem descender.

É evidente que uma visão isenta e crítica sobre a Ilíada e a Odisseia, bem como os estudos filológicos, históricos e arqueológicos gerados por essas obras, têm feito perpetuar o interesse por uma parte da história cuja cronologia avança num passado remoto. Não se pode, porém, afastar a atenção do epicentro desse interesse que é a "obra de arte literária em si", considerada como um todo, na medida em que ela é fonte de múltiplos significados e porta de entrada para uma Idade Heroica já irrecuperável no tempo. O tempo e a memória se entrelaçam nesse "discurso-rio". 
Há o eterno questionamento sobre a autoria dos poemas e sua fixação definitiva, o que Adrados (1984, p.35) designa como "[...] las teorías analíticas del núcleo y de la compilación [. . .]" e Jacqueline de Romilly (1983, p.187) como "[...] la querelle entre unitaires et analystes [...]", ressaltando-se que entre os extremos já surge uma terceira corrente conciliadora, a dos neo-analistas, representada pela pesquisadora Hélène J. Kakridis.

Os alunos interessados, que se propuserem a pesquisar essas teorias, notarão que elas mobilizam estudos respectivamente baseados em provas convincentes. Mas sempre é possível, no estudo dos poemas homéricos, perceber a simpatia dos autores menos radicais pela teoria unitarista, como Robert Aubreton (1968), que sugere a existência de um "núcleo geral primitivo" composto por um poeta convencionalmente conhecido como Homero. Esse pequeno texto original teria inspirado outros aedos que, por acréscimo, aperfeiçoaram o poema. Essa tese aponta para uma "epopeia primitiva" que teria sido a gênese de toda literatura.

A controvérsia é particularmente interessante à literatura, desde que concebida a partir do texto dos poemas enquanto fonte de questionamentos. Entretanto, à parte esse fato, um leitor leigo não se sente muito à vontade diante de estudos críticos que incluem mapas estratigráficos, plantas de escavações arqueológicas, cortes seccionados em diagonal, ou mesmo a superposição de antigas cidades arruinadas e recobertas de terra, como o fazem alguns autores, na tentativa de localizar referências que no texto da obra sinalizariam para índices reais (caso das "sete Troias"). Ao leitor sem base teórica para formular julgamento sobre assunto tão técnico e específico só resta ler, com atitude receptiva e atenta, relatórios de autores como Adrados, Blegen, Coindoz, Taylor, Cook e outros, percebendo que essa leitura comprova a atitude típica e característica do historiador que, em primeiro lugar, busca fatos, neles, a verdade, e nela, os alicerces que constituirão a história.

Deve-se sempre comentar com os alunos que, mesmo em assunto tão aparentemente árido, é possível divertir-se com o enfrentamento que, por vezes, ocorre entre os historiadores. E que há em certos textos dissabores recíprocos que afloram e com os quais os críticos literários se deliciam, como quando Blegen diz ser Schliemann "um romântico imorredouro" (In Vernant, 1990, p. 239), ou quando Finley (1991, p. 105), em Uso e abuso da História, critica indignadamente a arqueologia: "Se muitas vezes ocorre que a utilidade da arqueologia para a história cresce com o aumento da documentação, é também 
verdade que certos tipos de documentação tornam a arqueologia mais ou menos desnecessária [...]", e concluindo, diz: "Não é de surpreender, portanto, que o campo relativamente novo da arqueologia industrial continue estagnado. Eu ficaria muito mais surpreso se algum dia ela revelasse qualquer avanço."

Há ainda farpas rancorosas de Adrados (1984, p. 30) contra os críticos literários: "[. . . el crítico literario, en vez de tratar de comprender la obra que estudia, la juzga de acuerdo con su propio ideal literario." Deve-se notar, portanto, que é sempre de grande interesse dos estudiosos de diferentes campos do conhecimento, tanto na área científica (pesquisa histórica e arqueológica) quanto na literária (estudos linguísticos, filológicos, crítica textual), tudo que concerne a Homero e sua obra, sendo que para os estudiosos de literatura, professores, alunos e interessados em geral, as controvérsias vêm alimentar a ideia da variedade de opiniões possíveis e da fertilidade que os diferentes olhares podem deixar germinar, fazendo renascer a obra literária a cada nova leitura.

\section{Ficção e realidade}

Quanto a nós, professores e leitores, o que mais especificamente toca à literatura, porque atinge o ponto nevrálgico do 'fazer' literário, é o que se refere à questão: verdade versus ficção. A partir de que momento o 'feito' deixa o mundo da realidade para tornar-se um 'fato' ficcional?

No caso de Homero, isso ocorreu quando sua obra fixou-se na escrita. Os cabelos loiros e luxuriantes de Aquiles, mesmo que algum dia tenham sido verdadeiramente cortados num gesto "único", na ficção, a cada leitura, tal gesto se renova infinitamente. Os "níveos braços de Helena", para cada leitor, ganham contornos que a imaginação pinta esculturais, de acordo com os padrões de cada geração, também infinitamente.

Massaud Moisés (1988, p. 311), teórico e crítico literário, diz-nos que na própria origem a literatura condiciona-se à

[...] letra escrita, impressa ou não. Refere-se a uma prática que só pode ser verificada quando produz determinado objeto: a obra escrita. De onde não lhe pertencem as manifestações orais, ainda que de cunho artístico; enquanto não se registram em documento, 
inscrevem-se mais no folclore, religião, antropologia etc., que nos domínios literários.

Com essa fixação estabelecida é possível perceber o mecanismo de seleção feito pelo autor dos poemas sobre o volume de elementos de que ele dispunha e a ele chegados pela tradição. Sua contribuição pessoal é de fundamental importância na elaboração desses mesmos elementos, num processo que é essencialmente criação. É sob esse prisma que Romilly (1983) não concorda com a corrente que atribui a obra homérica a uma mera justaposição de pequenas composições à revelia, na medida em que existe nela uma carga de sens et d'intentions, segundo ela. Dotadas dos traços de criação, da elaboração e dos recursos essencialmente literários como as metáforas e as demais figuras, a Ilíada e a Odisseia podem ser consideradas de caráter ficcional.

Sobre a verossimilhança, não se pode negar que há no leitor uma espécie de sede de descobrir traços reais nos personagens, frestas por trás do rosto do herói que delineiem um rosto verdadeiro. E a prova histórica disso foi a euforia de Schliemann (In Vernant, 1990, p. 189) ao encontrar o que supunha ser o túmulo de Agamenon, comprovando os traços humanos em sua máscara mortuária.

Não se deve deixar de frisar que a própria conceituação de verdade é diferente no caso da história e da literatura. Para esta, toda caracterização deverá ser antes de tudo amoral, basta lembrarmos do escândalo provocado na época pelo livro Madame Bovary, que para muitos parecia incentivar o adultério. Flaubert teve de defender-se bravamente já que, segundo ele, não havia apologia a infrações morais, mas, sim, a descrição de um fato de caráter ficcional. Há ainda o que se conhece por "licença poética", que permite, por exemplo, na mitologia, atribuir à Aurora "róseos dedos", mesmo que ela não os tivesse ou mesmo que ela própria não fosse uma figura real.

Isto não exclui a possibilidade de que os "ouvintes" de Homero tivessem plena fé no realismo do que ouviam, como afirma Finley (1965, p.20), sentindo como se estivessem diante de uma realidade viva, acreditando no que deveria ter acontecido outrora, haja vista que "[...] a imaginação mítica implica sempre um ato de crença. Sem a crença na realidade do seu objeto, o mito perderia a sua razão de ser." Para este autor, além de poeta, Homero é um "contador de mitos e lendas" e, sob esse ângulo, enraizadas no real primitivo, teríamos nessas obras um 
documento histórico e linguístico, e não propriamente um texto ficcional. Outro é o ponto de vista de James E.Miller Jr. (1960, p.129) em Mith and Method, que no capítulo "Mith as Literature" afirma que "mito" significa "estória": "[...] mito é um conto, uma narrativa, um poema; mito é literatura e deve ser considerado como uma criação estética da imaginação humana [. . .]"

Certamente, o autor da Ilíada e da Odisseia não sabia que estava fazendo literatura/ficção, do mesmo modo que não poderia ter deliberada preocupação com a história. A atenção dos poemas dirige-se a alguns fatos passados, às vezes sem relacioná-los com outros. o que se sabe é que o aedo acreditava cantar inspirado pelos deuses e não ser sua, pessoalmente, a obra, mas da divindade que o inspirava: "[...] eu não tive mestre, o deus implantou no meu coração cantos de todas as espécies [...]" (Odisseia, XXII, v.347-348), nas palavras do aedo Fêmio.

Para os que só buscam correspondências factuais às referências do relato homérico, dando ao texto excessivo cunho histórico, há um capítulo interessante de Auerbach (1971, p. 10), “A cicatriz de Ulisses”, em seu livro Mimesis. É uma análise comparativa entre alguns aspectos da Odisseia e da Ilíada e o texto bíblico de Abraão e Isaac, que pode exemplificar muito bem o ponto sobre a verdade e a ficção no texto homérico. Nesse estudo, os heróis de Homero

[...] nos encantam e cativam de tal maneira que realmente compartilhamos o seu viver. Enquanto ouvimos ou lemos a sua estória, nos é absolutamente indiferente que saibamos que tudo é só lenda, que é tudo "mentira". A exprobração frequentemente levantada contra Homero, de que ele seria um mentiroso, nada tira de sua eficiência; ele não tem necessidade de fazer alarde da verdade histórica do seu relato, a sua realidade é bastante forte; emaranha-nos, embrulha-nos na sua rede, e isto lhe basta. Neste mundo "real", existente por si mesmo, no qual somos introduzidos por encanto, não há também nenhum outro conteúdo, a não ser ele próprio; os poemas homéricos nada ocultam, neles não há nenhum ensinamento e nenhum sentido oculto. É possível analisar Homero, como tentamos aqui, mas não é possível interpretá-lo [...] (AUERBACH, 1971, p. 10). 


\section{Considerações finais}

Quando consideramos os cursos que formarão historiadores, professores de literatura ou profissionais de quaisquer outras áreas vinculadas aos objetos e temas da cultura, não podemos perder de vista que, enquanto para a história é essencial que o "escrito", para poder passar à categoria de "documento", corresponda o mais proximamente possível à realidade inspiradora (e aqui não entramos na polêmica consideração de história como uma das possíveis leituras do passado, o que conferiria caráter ficcional ao conteúdo histórico), no caso da literatura, embora ela tendo como referência a experiência real humana, o imaginário atua no sentido de mesclar na ficção a projeção dos desejos humanos mais recônditos. Daí o sentido profundo de "catarse" que assume a obra literária, visando libertar, pela imaginação, o ser humano de suas limitações.

Vargas Llosa (1984, p. 11) diz muito bem que: "Una época no está poblada sólo de seres de carne y hueso; también de los fantasmas en que éstos se mudan para romper las barreras que los limitan [...]". Homero povoou o universo literário dos entes heroicos que sonhamos ser e que a vida real silencia. Talvez seja por isso que sua "verdade" ficcional prevaleça sobre tudo o que venha a ser dito, na medida em que seus simulacros possuem traços do Homem eterno.

Como o que é questionado no exemplo do texto de Homero é a possibilidade de separar dados biográficos da obra, também o ficcional (fruto direto do imaginário) do real/verdadeiro, fruto da comprovação (mesmo que duvidosa) da relação direta que o olhar científico empresta a suas conclusões e deduções, nos perguntamos: O que aprendem as novas gerações, os jovens de uma era da informatização crescente dos meios de comunicação e dos meios de vida com o que não seja fruto ou resultado da pesquisa científica e da tecnologia? Qual o lugar da ficção no mundo de hoje?

É incontestável que a sedução da tecnologia é assombrosa. Todos já se sentem incompletos sem os aparelhos que começam a fazer parte da vida cotidiana das pessoas em geral. E, apesar do paradoxo de termos mais conforto e acessibilidade e muito menos tempo disponível para atividades de lazer, vivemos num mundo que nos dá muito, mas também muito nos tira. Todos os que trabalhamos com educação somos levados diariamente a pensar nos rumos que será preciso dar à forma de aquisição dos conhecimentos e de que tipo de escola poderemos conceber para um mundo em processo dinâmico de mudança. 
Quanto à Literatura, o importante é não lhe dar a responsabilidade de trazer respostas. Os textos nos chegam como caixas de segredos que abrimos, descobrimos; de alguns desfrutamos mais, de outros menos. A experiência só valerá a pena "se a alma não for pequena". O professor pode trazer os textos, trabalhar com eles em sala de aula, colocar em apreciação os mais diferentes livros, ler alguns trechos, analisar alguns capítulos, apontar características interessantes que cada autor faz sobressair segundo seu estilo, época e capacidade de criar imagens, porém, a "catarse" referida acima é pessoal e intransferível. Totalmente pessoal e recôndita. Podemos "trazer" a literatura até o aluno, mas ensiná-lo a sentir o significado dos textos é no mínimo uma tarefa bem difícil pela própria natureza do objeto, pela própria especificidade do material tratado: apreensão de metáforas, captação de símbolos, compreensão das ironias sutis, estabelecimento de relação com experiências anteriores, antigas vivências e traços pessoais de gosto e preferências. Para tornar essa experiência mais verdadeira, o confronto com o texto deve dar-se sem a sombra da vida real do autor, sem a interferência que dados externos ao texto podem trazer, desviando o foco que precisa estar dirigido essencialmente à leitura. Depois disso, podem ser avaliados elementos externos, atalhos que de alguma forma esclareçam aspectos obscuros que impeçam a compreensão da ideia a ser entendida, porque não podemos pretender ser puristas e avessos a estudos críticos e análises de especialistas.

Quanto à história, deixemos que fique com suas tarefas de comprovação e de certezas; à literatura, a oportunidade de colocar-se como opção prazerosa frente à sobrecarga do mundo real. Talvez, se tiver de haver uma resposta à questão colocada sobre a invasão da tecnologia e seus efeitos em nosso trato com a ficção, seja possível dizer que a literatura pode preencher todos os vazios que vão ficando quando todos os demais campos de conhecimento enfraquecem nossas esperanças e nossos sonhos e nos deixam como crianças que, abandonadas na praia, ficam olhando o oceano à espera de algo não determinado. . .

\section{Referências}

ADRADOS, R. et alii.Introducción a Homero. [s/l/e] Labor/Punto Omega, 1984, vol.1. AUBRETON, Robert. Introdução a Homero. 2 ed. São Paulo: DIFEL/USP, 1968. AUERBACH, E. Mimesis. A cicatriz de Ulisses. Cap.1. São Paulo: Perspectiva, 1971. 
FINLEY, M.I. O mundo de Ulisses. Lisboa: Editorial Presença, 1965. . Os gregos antigos. Lisboa:Ed.70, 1984. Uso e abuso da História. Cap.5. São Paulo: Martins Fontes, 1991.

HEIDBREDER, Edna. Psicologias do Século XX. São Paulo: Paz e Terra, 1981.

KOTHE, Flávio. O herói. São Paulo:Ática, 1987.

MILLER JR, James E. Mith and Method. Minnesotta: Univ.Press, 1960.

MOISÉS, Massaud. Dicionário de termos literários. São Paulo: Cultrix, 1988.

ROMILLY, Jacqueline de. Perspectives actuelles sur l'époque Homérique. Paris:Presses Univ.de France, 1983.

VARGAS LLOSA, Mario. A mentira e a verdade na ficção. In: O Estado de São Paulo, Suplemento literário, 18/11/1984.

VERNANT, Jean-Pierre. Mito e pensamento entre os gregos. Rio de Janeiro: Paz e Terra, 1990.

recebido em 18 out. 2012 / aprovado em $1^{\circ}$ mar. 2013

Para referenciar este texto:

JARDINI, T. J. C. A pretexto de Homero. Dialogia, São Paulo, n. 17, p. 173-182, jan./jun. 2013. 